\title{
Final Report for the Soboba Strategic Tribal Energy Planning Project \\ U.S. Department of Energy Tribal Energy Program
}

Soboba Band of Luiseño Indians

$9 / 28 / 2013$ 


\section{Table of Contents}

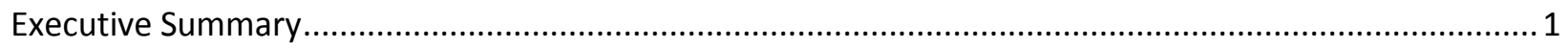

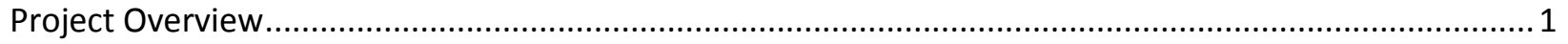

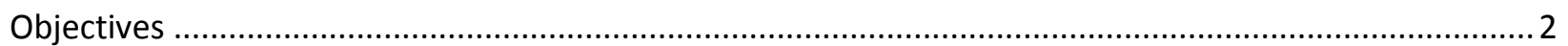

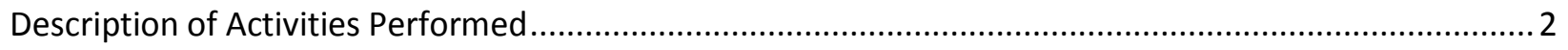

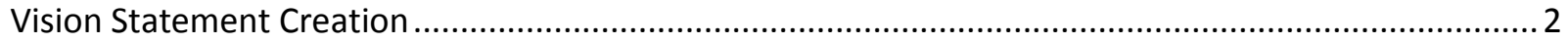

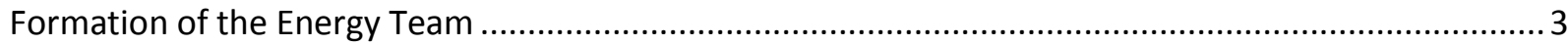

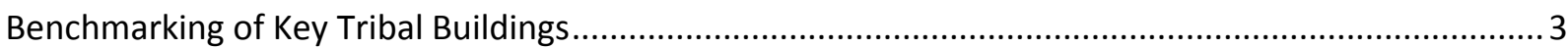

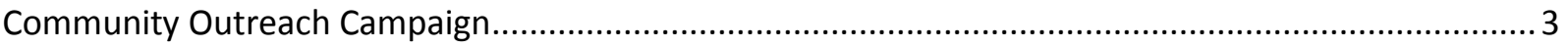

Determination of Energy Reduction Projects …............................................................................. 4

Completion and Approval of the Soboba Strategic Tribal Energy Plan .............................................. 4

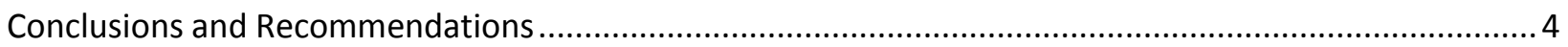

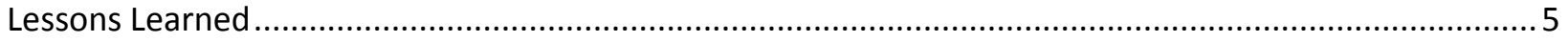

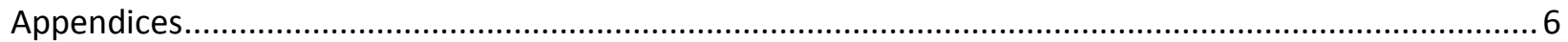

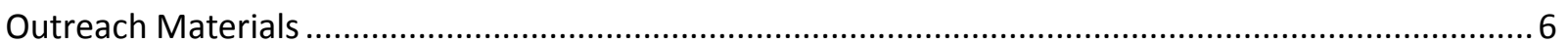

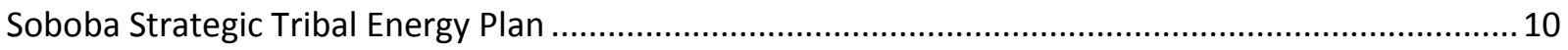




\section{Executive Summary}

In 2011 the Tribe was awarded funds from the Department of Energy to formulate the Soboba Strategic Tribal Energy Plan. This will be a guiding document used throughout the planning of projects focused on energy reduction on the Reservation.

\section{Project Overview}

The Soboba Band of Luiseño Indians is a Federally Recognized Indian Tribe, possessing sovereign status and powers by virtue of such recognition. The Tribe has an approved constitution and is governed by a five member Tribal Council, which is headed by a Tribal Chairperson. The current population of Tribal Members living on the Reservation is 490 and the total enrollment is approximately 1200.

The Reservation is located at the base of the San Jacinto Mountains, in the upper San Jacinto River Basin. The Reservation stretches eastward to the boundary of the San Bernardino National Forest, and westward and southward to the cities of San Jacinto and Hemet, respectively, in Riverside County, California. The Reservation consists of approximately 7,000 acres. The main facilities include the Administration building, Soboba Tribal Preschool, Noli School, Public Safety Department, Tribal Hall, Sports Complex, the Oaks and Public Works Department.

In 2009, the Tribe had an outside firm complete an "Energy Efficiency and Conservation Strategy Report." This document provided data regarding the Tribe's energy usage a, surveyed community members on their interest and attitudes towards renewable energy projects, and lastly conducted an initial evaluation of the Tribe's renewable energy potential. Several opportunities for cost cutting/efficiency projects had been observed, and implementation of these measures would have benefits for both fiscal and self sufficiency. After this report was completed, the order was given to develop a plan to address these findings. The Tribe determined that it would like to begin focusing on renewable energy sources and actively target the lowering the energy usage of the community.

In 2011 the Tribe was awarded funds from the Department of Energy to formulate the Soboba Strategic Tribal Energy Plan (SSTEP). This plan is a guidance document for the Tribe for the next five years to implement small, incremental gains in energy efficiency to achieve a $5 \%$ reduction in energy each year for a total reduction of $25 \%$. The focus of this plan was to determine how the Tribe as a whole could reduce energy usage rather than individuals. This resulted in a plan that focused on Tribal operations and facilities where implementation of a specific project would be most efficient with minor obstacles. In addition to identifying opportunities for energy reduction projects, the intention was to formulate a community outreach campaign strategy to assist in energy conservation and efficiency efforts. This not only makes residents aware of what is collectively being done to reduce energy, but also how individuals and employees can assist with conservation by behavior changes or specific product choices.

An Energy Specialist was hired to compile information, produce outreach materials, and analyze energy project options for the Tribe. The Energy Specialist worked with the Environmental Director, Public Works Director, and Information Technology Direct as a Strategic Energy Team to identify areas with the 
most potential for successful completion of energy reduction projects. This team was selected to combine areas of expertise that would have the most direct connection with any energy project proposed or implemented.

Outreach materials created included brochures, newsletter articles and emailed "energy tips." These materials were provided to the community as well as Tribal Administration staff. An Energy Fair was held to gather feedback from the community, provide outreach information related to energy efficiency and reduction, and to allow the community an opportunity to interact with business/organizations relevant to energy use reduction.

Project documentation consisted of quarterly reports to DOE, a final SSTEP document approved by Tribal Council, the final report submitted to DOE, and a presentation at the annual DOE meeting in Colorado. The SSTEP document and a selection of outreach material are included as appendices to this report.

\section{Objectives}

The primary goal of this project was to enhance tribal self and fiscal sufficiency. This was to be accomplished through the reduction of $5 \%$ energy each year for the next five years to result in a total $25 \%$ reduction from baseline energy use. There were three objectives developed to complete this goal for the Soboba Strategic Tribal Energy Project.

1. Produce a five year energy vision statement for the Soboba Tribe to include a minimum $5 \%$ benchmark reduction in energy usage for each year.

2. Produce a five year action plan to include specific "demand side" and "supply side" energy reduction projects.

3. Produce a corresponding community outreach campaign for addressing benchmark energy reduction goal

All of these objectives were completed during the project. The plan for energy reduction projects is seen as the first steps towards energy management for the Tribe and a guide for decision making on future project implementation. It is acknowledge that rapidly changing technology in the energy efficiency and renewable energy fields make it difficult to lay forth a specific path and timeline of energy reduction products. The document is flexible enough to provide several paths for action depending upon tribal priorities, current technology, and financial considerations while still striving towards the primary energy reduction goal. The community outreach campaign was initiated with the intention of continuing it throughout the next five years during the duration of the energy reduction projects.

\section{Description of Activities Performed}

\section{Vision Statement Creation}

It was desired that the vision statement encompass not only the idea that the Tribe wants to reduce energy, but that this project will be incorporated as part of the overall desire to preserve the land and 
environment for tribal members past, present and future. The vision statement is not a mandate towards energy use reduction. Instead it is intended to motivate everyone to think about their individual and organization activities' impact on all areas of energy consumption. With those ideas in mind, the following vision statement was created:

"We will better our children's future by not being wasteful in our lives. To accomplish this, we will create within our operations those habits that inspire individual and organizational decisions that lead directly to reducing energy use, water use, and waste production at our buildings and facilities."

\section{Formation of the Energy Team}

The energy team was formed to guide the creation of the SSTEP with knowledge of the main tribal departments that would implement projects or were most closely related. This included the Environmental Department, Public Works Department, and Information Technology Departments. All of these departments helped assess feasibility of possible projects or technology implementation. Additionally there were able to provide insight into areas that needed improvement even before additional data was analyzed. In addition to these departments, representatives from Southern California Edison (SCE) were contacted and worked closely with the Energy Specialist. SCE is the sole provider of the Tribe's electricity and provided utility usage data, new technology information, and guidance on cost information/rebate availability.

\section{Benchmarking of Key Tribal Buildings}

Baseline conditions were determined for the main Tribal building as a benchmark for future progress. Energy Star's Portfolio Manager was used to monitor usage and any effects conservation efforts. The Administration building, Public Safety offices, Tribal Hall and Soboba Preschool buildings were chosen to begin the process of benchmarking Tribal buildings. The decision to implement this program in these buildings first was influenced by the ease of monitoring, including online access to bills and the ease of obtaining updates. Even during the one year of monitoring, figures for total energy usage for these buildings decreased indicating a likelihood of at least some degree of effectiveness in the community outreach efforts.

\section{Community Outreach Campaign}

A community outreach campaign was developed an initiated during this project period. To date the campaign has been mainly directed towards the Tribal employees but the Tribal Members and residents of the Reservation were included on occasion as well.

Projects implemented include:

- Monthly e-mail tips to the employees

- A survey of Tribal Members about energy efficiency awareness/practices and what sort of renewable energy (or other related programs) they might be interested in 
- Design and production of small reminder signs to turn off the lights placed throughout Tribal buildings near light switches

- An Energy Awareness Month with three presentations by different entities offered to all employees

- Design and production of a conservation poster

- Design and printing of five three-fold brochures on various energy conservation areas (electricity, natural gas/propane, recycling, carbon dioxide and gasoline) that were available at event and the Environmental Department website

- Three articles for submission to the Environmental Department's quarterly newsletter

- An Energy Fair with 18 different agencies and local businesses invited and over 150 Tribal Members and employees in attendance. There was also a survey conducted after the event to determine if it was effective in promoting energy awareness and the attitude of attendees regarding a desire to learn more about energy conservation and alternative energy projects.

\section{Determination of Energy Reduction Projects}

Several specific projects were identified and included in the SSTEP that would assist in accomplishing the energy reduction goal. These projects included projects that could be implemented easily and immediately along with projects that are more complex and farther off in implementation. Not only were efficiency and conservation projects considered, but some renewable energy options were identified as well. The energy reduction projects can be found in the SSTEP document.

\section{Completion and Approval of the Soboba Strategic Tribal Energy Plan}

The SSTEP is a guidance document for future decision making regarding energy use and projects. Through incorporating the experience of several departments and outside entities with technical expertise, this plan has several options of projects that the Tribe can immediately move forward with and that are likely to be great successes. The plan summarizes energy use, outlines community outreach strategies, and identifies projects that can be implemented to achieve the energy reduction goal. The final version of this plan was approved by Tribal Administration and Tribal Council. The plan has been made available to the community for distribution.

\section{Conclusions and Recommendations}

The Soboba Strategic Tribal Energy Planning Project was helpful in bringing focus to how easily energy reductions can be made and highlighted the areas where there is room for improvement. There are several relatively simple projects that were identified to readily meet the energy reduction goals. One project had such significant energy and cost savings that it was implemented before the project period was over. The SSTEP will be a valuable document moving forward that provides easy to follow guidelines that can meet the energy reduction goal without much difficulty. The SSTEP will provide a useful reference for several departments' operations to move the Tribe towards energy efficiency and 
conservation. The document should be kept current and referenced whenever doing future project planning or any improvements where an occasion to incorporate energy reduction measures may arise.

The community outreach campaign conducted showed an interest in energy reduction once individuals were made aware of issues and opportunities. It would be beneficial for the outreach material that was created to continue to be made available and the outreach plan in the SSTEP to be followed through. The Energy Fair had a significant turn out and the surveys conducted the event indicated people would attend again. If possible, an annual Energy Fair would be useful in continuing the education and outreach for the community. Through the community outreach, it was determined that there is interest in renewable energy on the individual level and future efforts could include more focus on that area. Interest was also high in technology that is energy efficient and it would be prudent moving forward to heavily incorporate those methods of conservation.

The next step is to follow through with several, if not all, of the projects identified. A full time energy program with dedicated staff would be helpful to do this and keep informed on the most up to date technology and projects that could assist with energy use reduction.

\section{Lessons Learned}

An important issue of note that there was some resistance towards the plan before the purpose of the document was clarified. Many people were mistaken that it was a document consisting or rules and project mandates that would be onerous to follow and make meeting specific energy reduction goals and burden on staff. When it was pointed out that the plan was a guide and there were projects as simple as switching out light bulbs included, the majority of resistance ceased. In the future, it is important to be clear about what energy projects and programs entail with an emphasis on the impact simple and easy projects can have.

It was found that behavioral changes are much harder to implement than technological changes. Even when awareness was raised, signs posted, and reminders sent out, people still engaged in wasteful behavior such as leaving on lights when they left the room. It was determined to be more reliable and result in greater savings to reduce what an individual has to remember to do or not do by incorporating technology that does this for them or that is more energy efficient to begin with.

The interest in renewable energy was much greater than we initially anticipated. In the future, more information should be provided about these options. Renewable energy could also be used as a gateway into getting the community more interested in efficiency and conservation which did not result in as much interest. 
Appendices

Outreach Materials 


\section{Piláchin 'ivím 'atáaxum 'óongay "The people will learn from you"

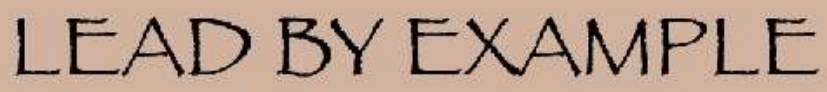

Teach the young these important tips:

CONSERVE WATER AND ELECTRICITY

- NURTURE THE EARTH

- RECYCLE, REDUCE and REUSE

BY INSTILLING THESE SIMPLE LESSONS IN OUR YOUTHYOUARE ENSUREING A FUTUURE FOR GENERATIONS TO COME.

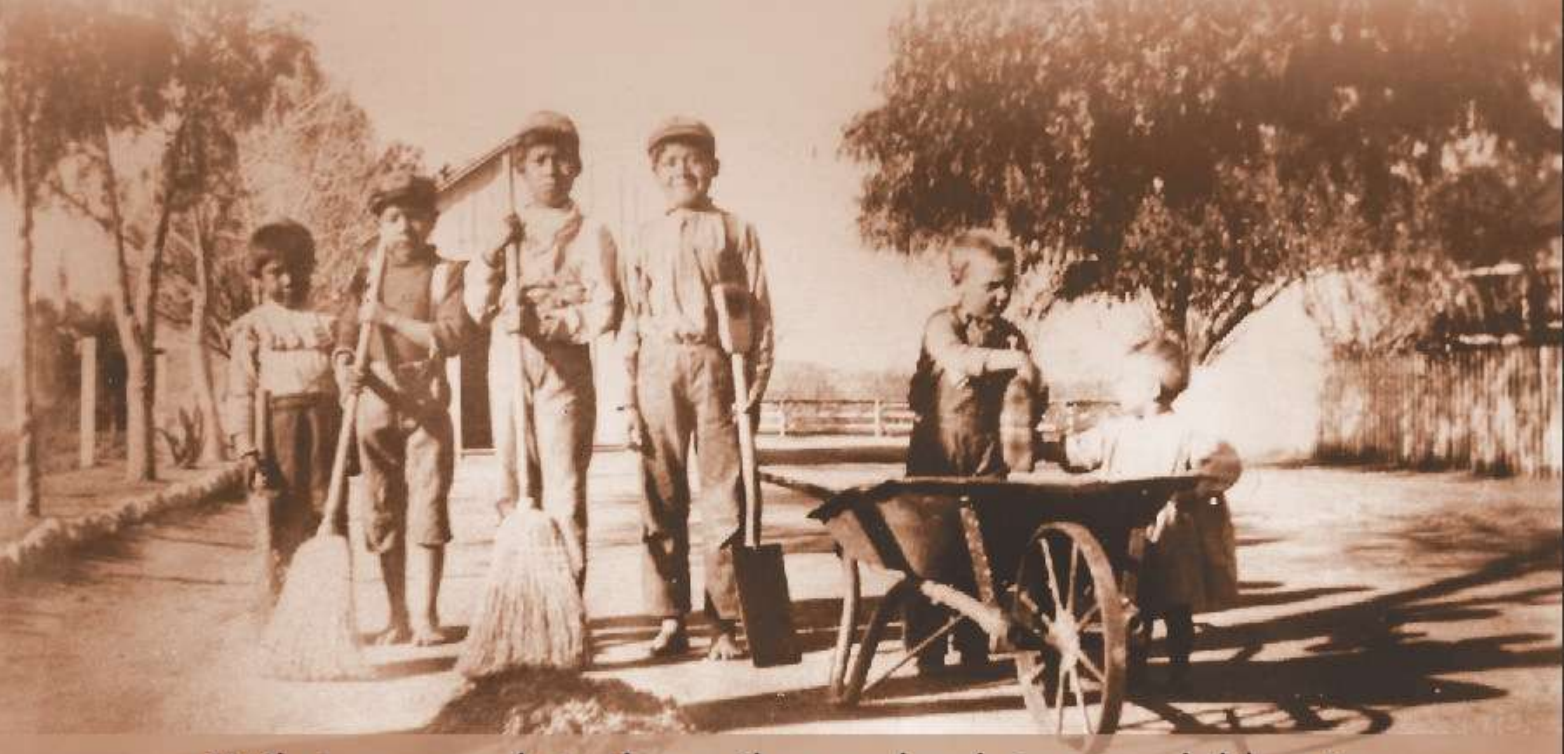

"Whatever you do to the earth, you also do to your children." - American Native wisdom 


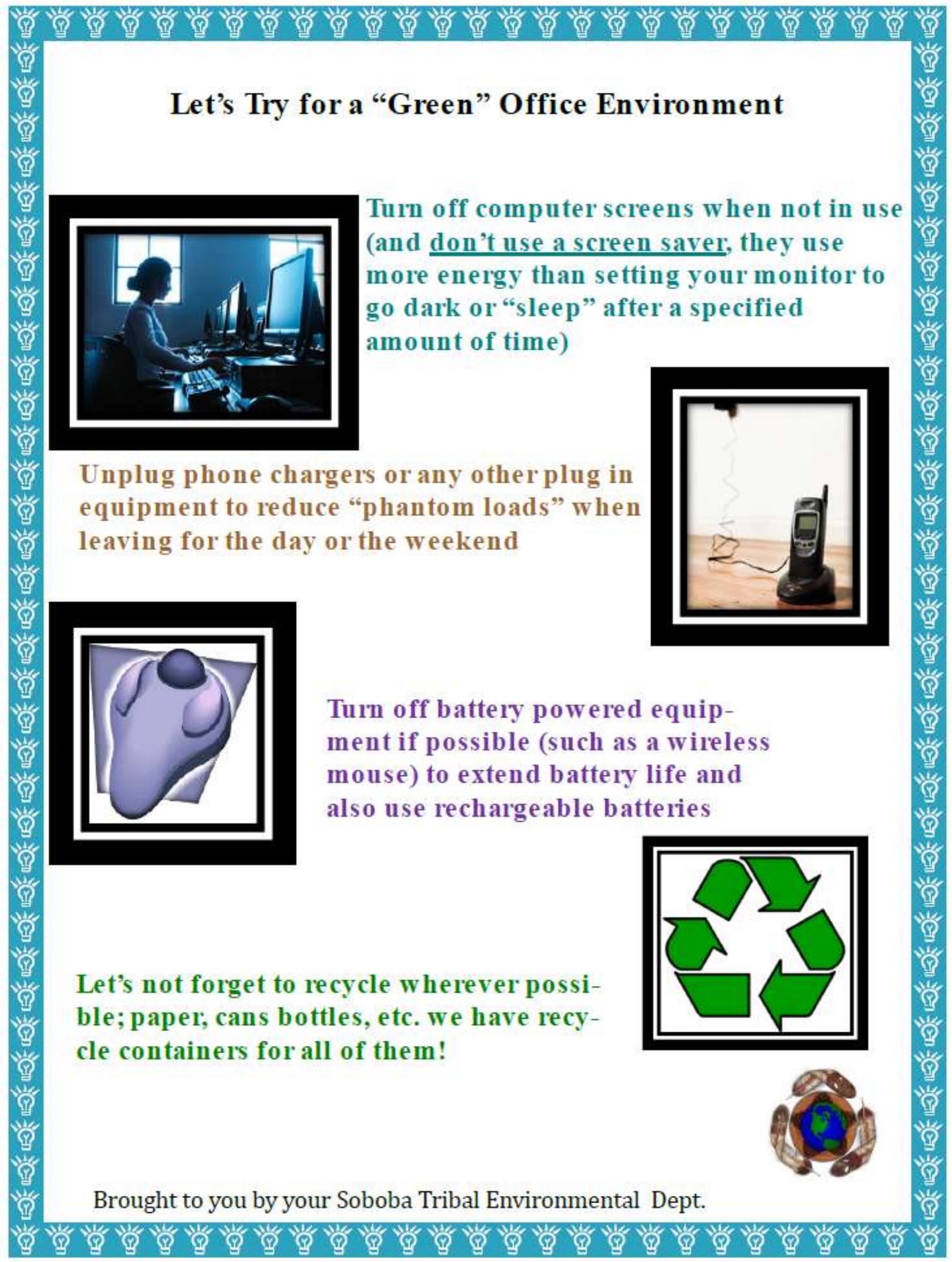



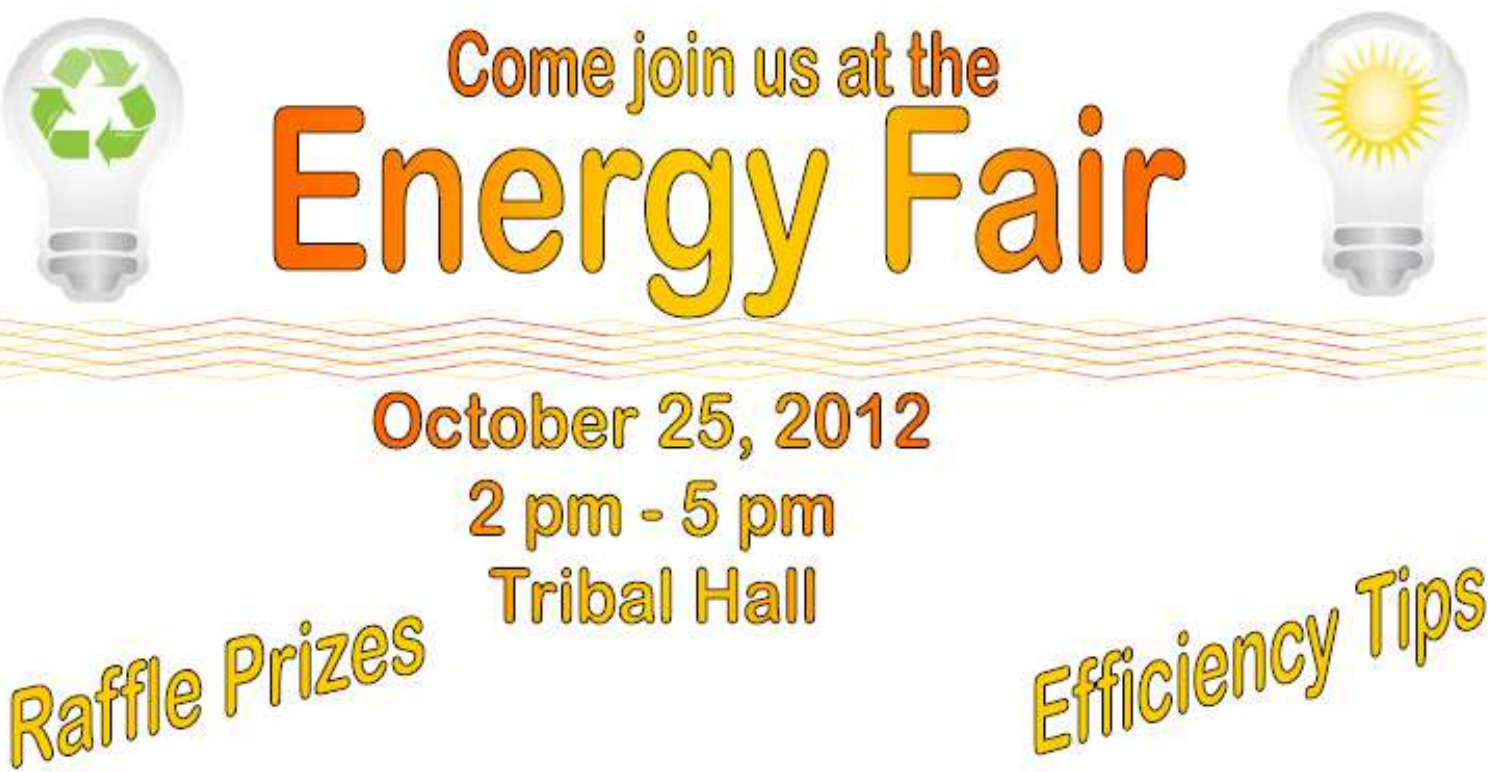

The Environmental Department will be hosting an energy fair to help spread energy awareness. There will be information about ways to save energy, use energy efficiently, and representatives from different entities that offer programs or services to help you save. We will also have vendors there in case you are interested in solar energy or other alternative energy ideas.

\section{Renewable Info Save money \\ Energy Products}

If you have any questions, contact the Soboba Tribal Environmental

Department's Energy Specialist at (951) 654-5544 x 4128 
Soboba Strategic Tribal Energy Plan 


\section{Soboba Strategic Tribal Energy Plan (SSTEP)}

Soboba Tribal Environmental Department

September 2013

Soboba Band of Luiseño Indians

23906 Soboba Road, San Jacinto, CA 92583 Telephone: (951)654-2765 
SSTEP 2013

\section{Soboba Band of Luiseño Indians Tribal Council}

P.O. Box 487 San Jacinto, CA 92581 Phone: (951) 654-2765

Fax: (951) 654-4198

- $\quad$ Rosemary Morillo

Chairwoman

- $\quad$ Edward Soza

Vice Chairman

- $\quad$ Geneva Mojado

Secretary

- $\quad$ Pamela Miranda

Treasurer

- Jacob Briones

Sergeant at Arms

\section{Energy Team}

Erica Helms-Schenk - Environmental Director

Gwenda Rose - Environmental Assistant

Kimberly Miller - Environmental Specialist

Dianna Greetan - Energy Specialist

Steven Nino - Information Technology Director

Ken McLaughlin - Public Works Director

Joseph Ageman - Public Works Project Manager

Gerald Wilson and Brian McDonald - Southern California Edison Representatives 
SSTEP 2013

\section{Contents}

Objectives

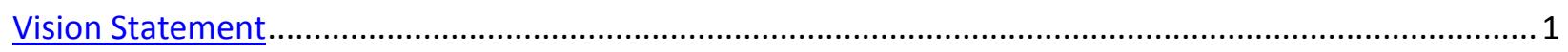

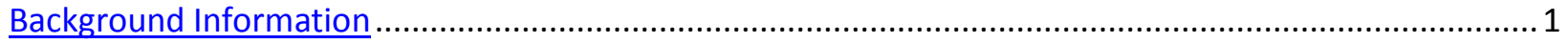

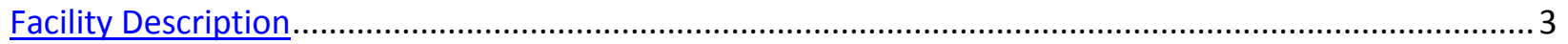

Initial Energy Usage

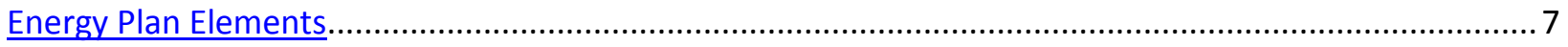

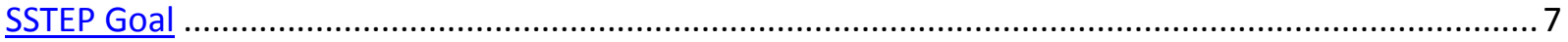

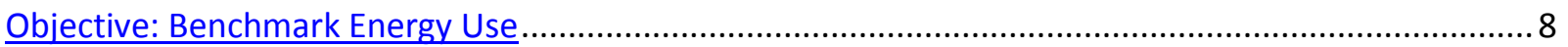

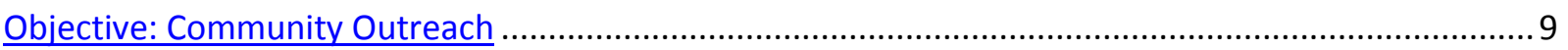

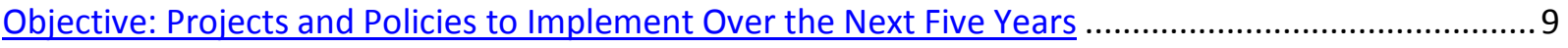

Year One: Continue conservation efforts with "low-hanging-fruit" projects ...................................... 9

Years Two and Three: Build upon initial projects ........................................................................ 11

Years Four and Five: Implement advanced projects..................................................................... 14

New Construction

New construction projects should implement green building practices .............................................. 17

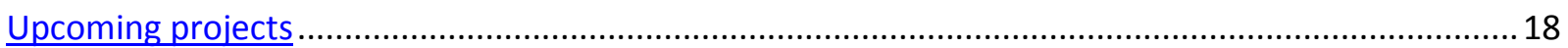

Transportation

Summary of current vehicles, current fuel usage, and suggestions for improvement .........................19

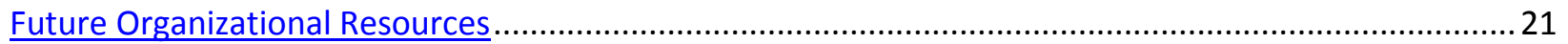

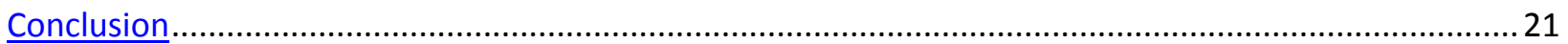

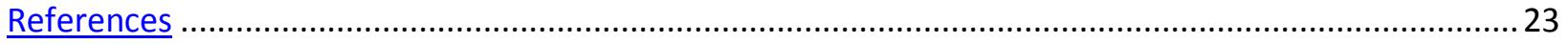




\section{Objectives}

The Soboba Strategic Tribal Energy Plan's goal is to create a Five Year Energy Plan for the Soboba Band of Luiseño Indians in San Jacinto, California. This plan will guide the decision making process towards consistent progress leading to the Tribal goal of a $25 \%$ reduction in energy consumption in the next five years. It will additionally outline energy usage/patterns and will identify areas the Tribe can decrease energy use and increase efficiency.

\section{Vision Statement}

"We will better our children's future by not being wasteful in our lives. To accomplish this, we will create within our operations those habits that inspire individual and organizational decisions that lead directly to reducing energy use, water use, and waste production at our buildings and facilities."

This Vision statement was established to support the Tribal goal of a 5\% annual decrease in power usage over the next five years for a total goal of 25\% reduction from 2012 baseline levels. In doing this, the Tribe is taking care of the natural resources to benefit the generations to come.

\section{Background Information}

In order to understand the Soboba Band of Luiseño Indians, it is necessary to understand the indigenous environment which fostered the development of the Soboba culture. In looking to a future of promise and positive potential, Soboba looks to its past. The Tribe was originally the steward for natural resources of millions of acres of land and water located in Southern California. Those resources sustained the Soboba people for thousands of years.

Although the people of Soboba recognize that their environment will never return to the pristine condition they enjoyed in pre-historic times, they are also cognizant that the survival of their culture is directly linked to the health of the environment. The Soboba Band of Luiseño Indians will utilize this Tribal Energy Plan in protecting and enhancing the Tribal environment. 
The Soboba Band of Luiseño Indians is a Federally Recognized Indian Tribe, possessing sovereign status and powers by virtue of such recognition. The Tribe has an approved constitution and is governed by a five member Tribal Council, which is headed by a Tribal Chairperson. The current population of Tribal Members living on the Reservation is 490 and the total enrollment is approximately 1200 .

The Reservation is located at the base of the San Jacinto Mountains, in the upper San Jacinto River Basin. The San Jacinto River flows along the southern boundary of the Reservation. The irregular configuration of the Reservation stretches eastward to the boundary of the San Bernardino National Forest, and westward and southward to the cities of San Jacinto and Hemet, respectively, in Riverside County, California. The existing Reservation is surrounded by vacant land and low-density rural residential development, and is comprised of rolling hills, deep ravines, river bottom, and a fairly level alluvial fan near the San Jacinto River.

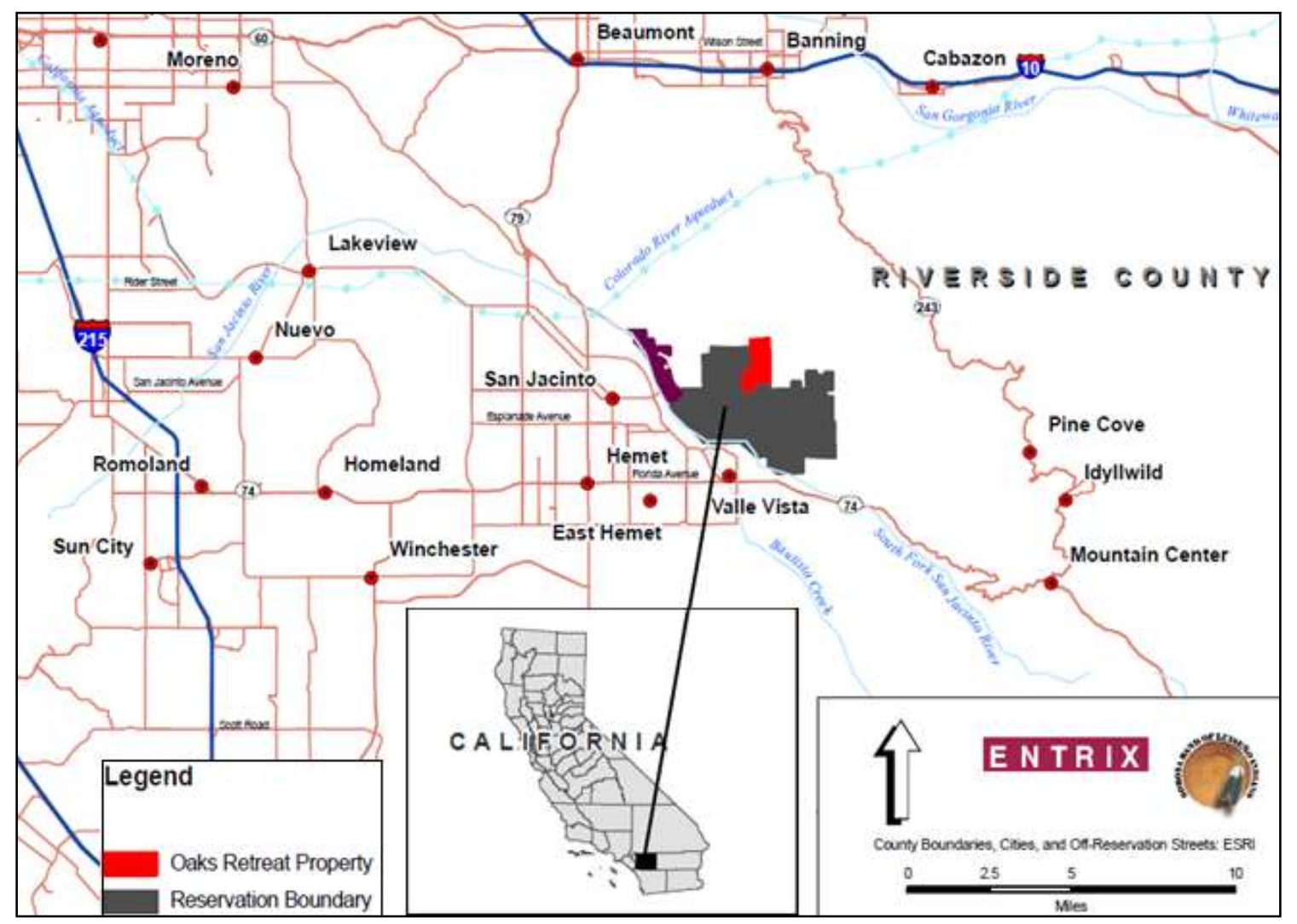

The Reservation consists of approximately 7,000 acres, 400 of which are residential. The Administration building, Soboba Tribal Preschool, Noli School, Public Safety Department, 
Tribal Hall, Sports Complex, and Public Works Department are also within those 400 acres. The facilities at The Oaks are outside of this residential area.

In 2011 the Tribe was awarded funds from the Department of Energy to formulate the Soboba Strategic Tribal Energy Plan. This will be a guiding document used throughout the planning of projects focused on energy reduction on the Reservation. The majority of the Tribe's energy is electricity purchased from Southern California Edison (SCE). SCE's 2011 energy power content label showed that actual energy production was sourced from $27 \%$ natural gas, 24\% nuclear , 19\% eligible renewable, 8\% coal, 7\% large hydroelectric and $15 \%$ unspecified sources of power.

\section{Facility Description}

This plan primarily focuses on Tribal buildings/operations and not individual residents or homes. Although the plan itself does not focus on the residents of the Reservation, the outreach campaigns do encourage the residents to make energy reductions of their own. The electric bills are divided up by SCE into separate bills based on the area served. The following photographs and basic descriptions include the facilities that were focused on for this project. Each photo and description comprises one energy bill area 


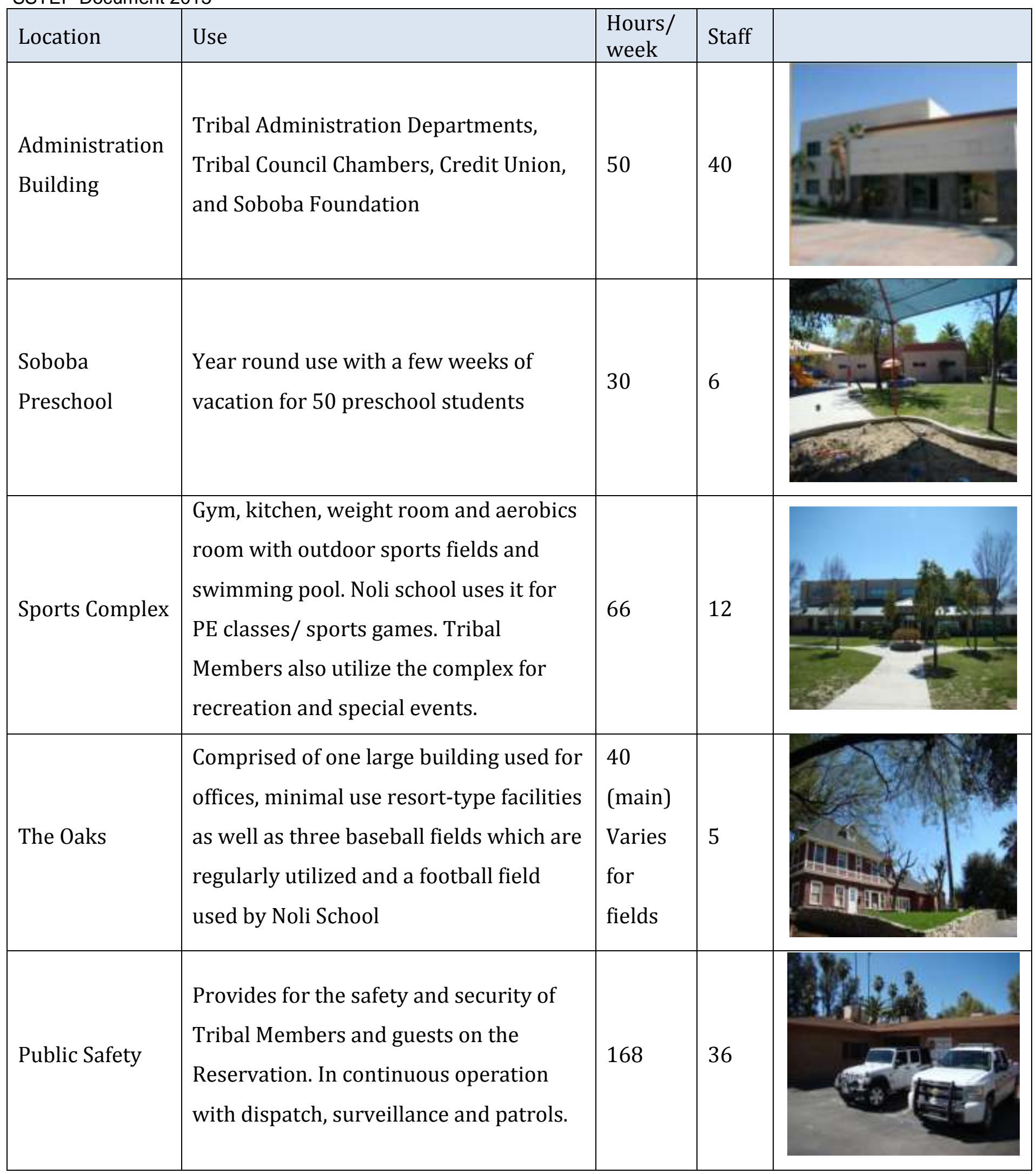




\begin{tabular}{|l|l|l|l|l|}
\hline Location & Use & $\begin{array}{l}\text { Hours/ } \\
\text { week }\end{array}$ & Staff \\
\hline Public Works & $\begin{array}{l}\text { Responsible for streets, public buildings, } \\
\text { water, street lighting and maintenance. } \\
\text { Maintenance for Tribal vehicles is also } \\
\text { conducted. }\end{array}$ & 45 & 12 \\
\hline Tribal Hall & $\begin{array}{l}\text { Community building available for Tribal } \\
\text { business and Tribal Member functions } \\
\text { with meeting room and kitchen. Booked } \\
\text { by appointment and available, but not } \\
\text { necessarily in use, seven days per week. }\end{array}$ & varies & 0 \\
\hline Noli School & $\begin{array}{l}\text { Middle and High School with } \\
\text { approximately 125 students and 19 } \\
\text { portable buildings. Open Monday } \\
\text { through Friday for approximately ten } \\
\text { months out of the year. }\end{array}$ & $\begin{array}{l}\text { Three water pump houses supply water } \\
\text { for the Reservation and landscaping. }\end{array}$ & 168 \\
\hline \multirow{5}{*}{ Pump Houses }
\end{tabular}




\section{Initial Energy Usage}

The following graph depicts the average commercial office building energy usage in the United States according to data collected by the U.S. Department of Energy. This is helpful to assess where most of the energy is expended and areas that may be the easiest to target for the highest benefit. Lighting and space heating/cooling are the largest categories of energy expenditure for the commercial sector.

\section{Commercial Energy Site End-Use Splits}

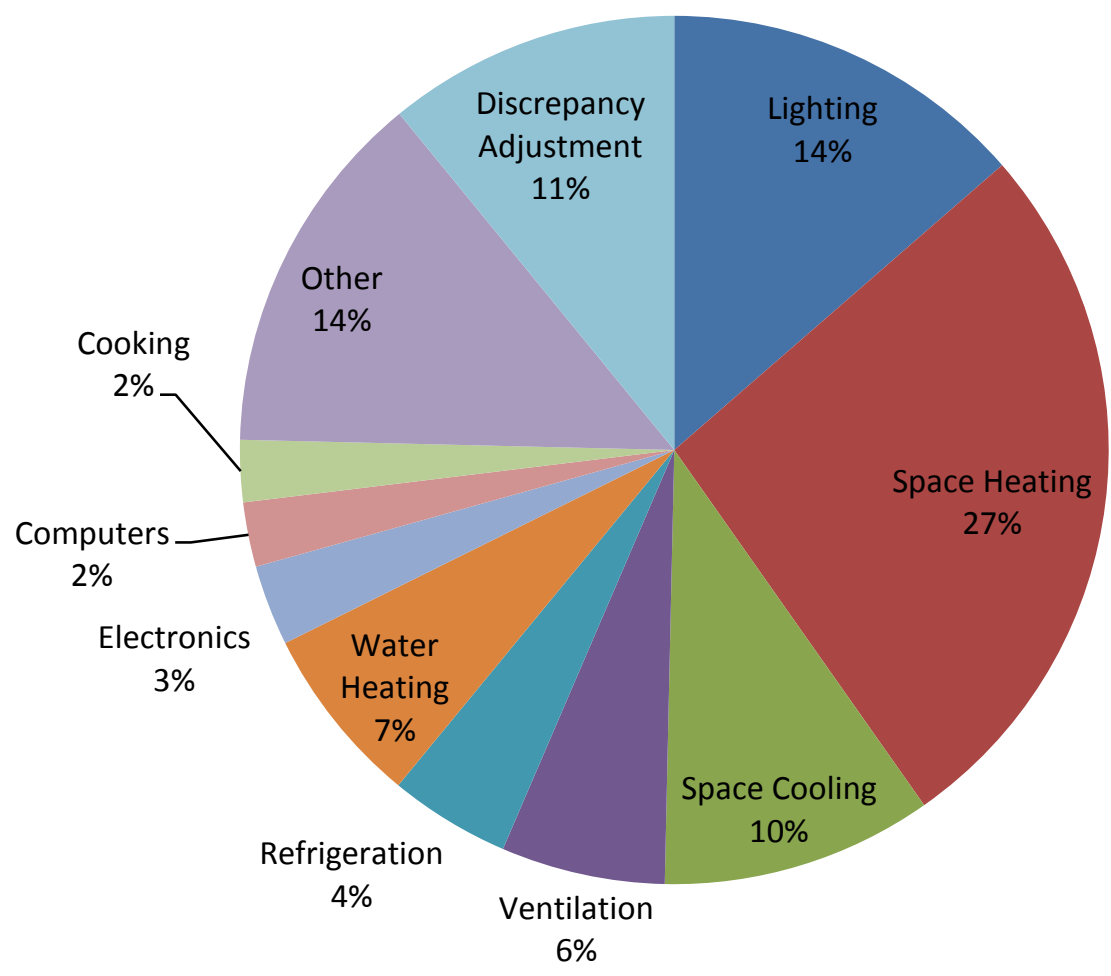

The next graph shows Soboba's electrical energy usage for 2012 in kilowatt hours (kWh). These figures were obtained from the SCE power bills for the specified facilities. The pump houses encompass the largest individual use area out of these facilities with the Sports Complex and Tribal Administration buildings being the next highest electricity consumers. 


\section{Total Energy Use}

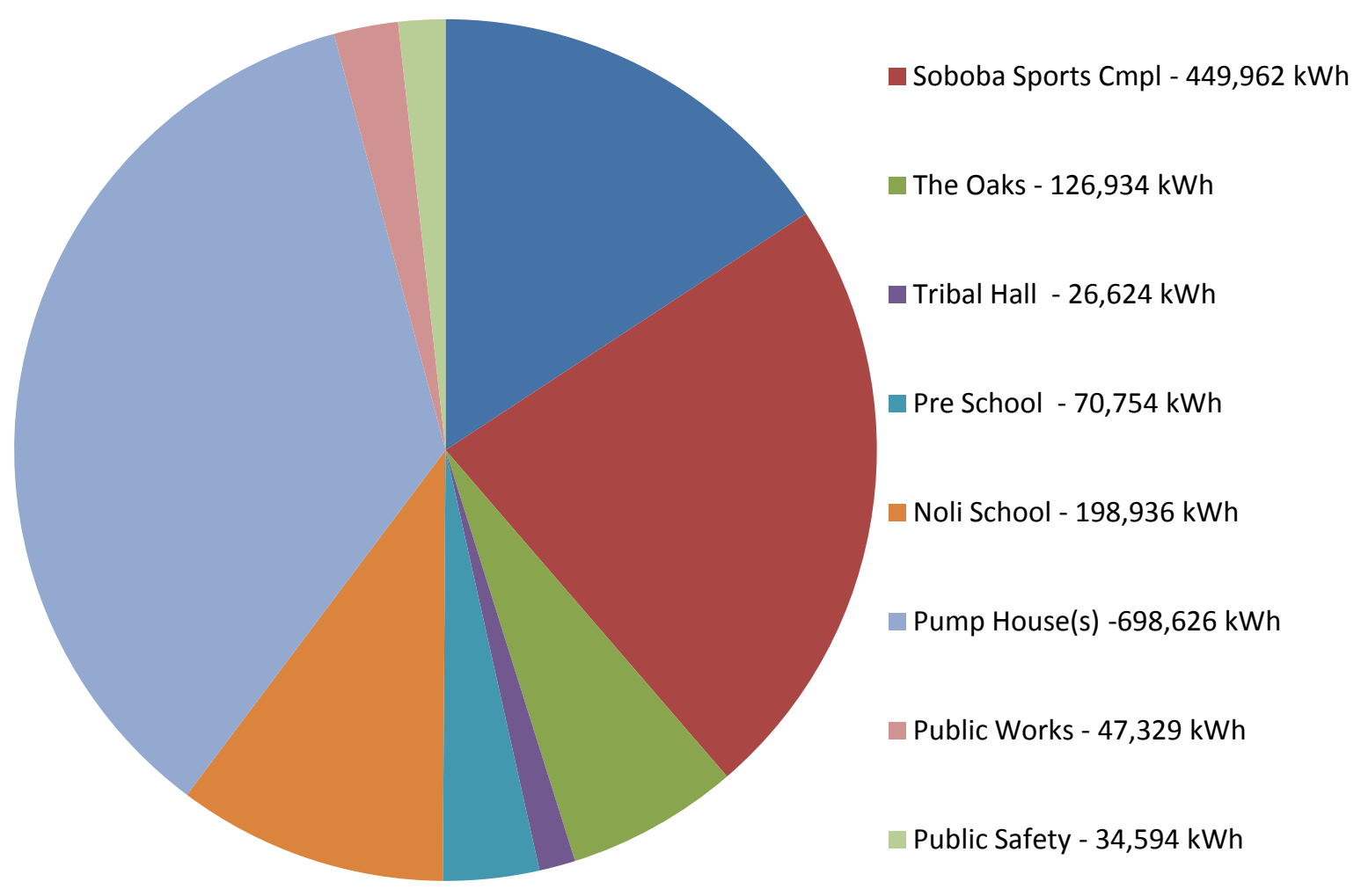

Soboba uses natural gas for some building and water heating, but is focusing on electrical usage rather than gas, as that is the main form of energy used (13\% of energy was gas and 87\% was electrical in a NESCO 2010 study). The Tribe is addressing reducing natural gas usage by adjusting building thermostats to reduce heating. Public Works is also checking on the necessity of insulating hot water tanks; at least two of them in the public buildings are completely enclosed and protected. The thermostats for the hot water tanks can also be checked and adjusted if their temperatures are set above $120^{\circ}$ Fahrenheit. As the Tribe begins to make improvements reducing electrical use and increasing efficiency, more focus can be placed on reducing natural gas consumption.

\section{Energy Plan Elements}

SSTEP Goal 
Reduce energy consumption 5\% each year from the 2012 baseline amount over the next five years for an overall reduction of $25 \%$ from 2012 usage and begin to focus on renewable energy.

- Tribal electrical power usage for 2012 totaled approximately 1,899,364 kWh.

- This results in the need to lower consumption annually by approximately $94,968 \mathrm{kWh}$ for each of the next five years.

- The Tribe will actively pursue the use of solar energy in at least one project within the Five Year Plan.

There are several methods the Tribe decided to employ to go about achieving this goal. Objectives that would work towards decreasing energy usage were identified. The Tribe realizes that the use of solar energy does not reduce power consumption. However, the use of renewable energy technology does decrease the need for energy produced by fossil fuels and helps protect the environment by lowering green house gas emissions. These objectives are explained below.

\section{Objective: Benchmark Energy Use}

The first step to decreasing energy usage is to determine baseline conditions as a benchmark for future progress. Energy Star has an online application called Portfolio Manager in which utility information for individual buildings can be input and monitored in order to stay informed of usage and conservation efforts. The Administration building, Public Safety offices, Tribal Hall and Soboba Preschool buildings were chosen to begin the process of benchmarking Tribal buildings and see if initial community outreach projects regarding energy efficiency and conservation would have results in lowering energy usage in these facilities. The decision to implement this program in these buildings first was influenced by the ease of monitoring, including online access to bills and the ease of obtaining quarterly updates.

Monitoring energy use began with figures from July 2012. The first update done at the end of October 2012 showed decreased energy consumption in two of the four benchmarked facilities. The second update at the end of January 2013 showed a cumulative decrease of 
2\% total energy for all four buildings, with the Public Safety building achieving the highest individual reductions at $16 \%$ of its initial usage.

\section{Objective: Community Outreach}

The Energy Specialist conducted a consistent community outreach campaign since being hired in July 2012. To date the campaign has been mainly directed towards the Tribal employees but the Tribal Members and residents of the Reservation have been included on occasion as well.

Projects implemented to date include:

- Monthly e-mail tips to the employees

- A survey of Tribal Members about energy efficiency awareness/practices and what sort of renewable energy (or other related programs) they might be interested in

- Design and production of small reminder signs to turn off the lights placed throughout Tribal buildings near light switches

- An Energy Awareness Month with three presentations by different entities offered to all employees

- Design and production of a conservation poster

- Design and printing of five three-fold brochures on various energy conservation areas (electricity, natural gas/propane, recycling, carbon dioxide and gasoline)

- Three articles for submission to the Environmental Department's quarterly newsletter

- An Energy Fair with 18 different agencies and local businesses invited and over 150 Tribal Members and employees in attendance. There was also a survey conducted after the event to determine if it was effective in promoting energy awareness and the attitude of attendees regarding a desire to learn more about energy conservation and alternative energy projects.

Objective: Projects and Policies to Implement Over the Next Five Years Year One: Continue conservation efforts with "low-hanging-fruit" projects

Low hanging fruit projects are easily instituted and can encourage support for large, more complex projects by creating identifiable successes. Some projects discussed in this section 
have already been started or the groundwork has been laid. Year One projects will be used to show the benefits of small and practical changes.

- Continue the successful "Turn off the lights" campaign. Emphasis on this small behavioral change has increased general awareness and encouraged participation in energy conservation by creating an easy first step with limited resistance.

- Reflective window film should be installed on the southwest and western facing windows to reduce heat from direct sunlight in the summer on all appropriate public buildings.

- Doors on the public buildings should be checked and fitted for proper insulation strips. This should be checked annually, as the strips can easily wear off.

- Adjust the thermostats in all the buildings to US Environmental Protection Agency (EPA) recommendations $\left(68-70^{\circ} \mathrm{F}\right.$ for heat in the winter and $76-78^{\circ} \mathrm{F}$ for air conditioning in the summer), as this saves both electricity and natural gas. This step, which would have no cost, could save $4 \%$ annually on the heating, ventilation and air conditioning (HVAC) energy usage on the buildings where HVAC is the major expense (Public Works, Noli, Public Safety, Administration building, Tribal Hall, and the Preschool). This would come out to a reduction of approximately $8,980 \mathrm{kWh}$ annually.

- Installation of simple technological fixes is recommended for implementation throughout public buildings. This includes occupancy sensors so lights and computers automatically turn off (computers can be set to sleep mode) when an area is unoccupied for a specified amount of time. Also timers for all the Sports Complex lighting could be installed so lights are not accidently left on after an event. Occupancy sensors and timers are items that currently have rebates through Southern California Edison. The budget for these sorts of projects is very low and costs would most likely be recouped within less than a year.

- The Tribe should consider if solar projects are feasible to begin planning. The Tribe has had previous professional evaluations conducted to assess the possibility and feasibility of solar projects for several facilities. The Tribe will move forward with the review of these evaluations to determine which projects, if any, will best suit the needs of the 
Reservation and serve as a pilot project to better acquaint the Tribe with the use of solar energy.

In order to progress with this energy plan, the above items need to be completed, even though these measures alone will not allow the energy reduction goals of $5 \%$ each year to be reached. Completing these initial items will provide a foundation for future projects with greater energy savings. Use of renewable energy sources, specifically solar energy, has been discussed by the Tribe as a possibility to investigate. Development of solar energy would reduce the need for standard grid energy, and likely be incorporated into future projects. If more sustainable energy sources are to be included in the Tribe's energy portfolio, current buildings should be as efficient as possible in order to have a system that would meet the Tribe's needs and be as cost effective as possible.

\section{Years Two and Three: Build upon initial projects}

- Conduct community outreach/education projects for the schools on the Reservation. Projects could be done on a semester or yearly basis with each age group at the schools: preschool, middle school and high school. These outreach projects would be spearheaded by the Soboba Tribal Environmental Department in partnership with the appropriate School Administrator and/or teacher at each grade level. The US Department of Energy (DOE)'s Energy Efficiency and Renewable Energy program has energy conservation projects for K-12 grade levels that could be easily adapted for presentation at Reservation schools. They are designed to be used in the classroom with some supplemental activities taking place at home. Each of the projects gives the students the opportunity to learn about energy conservation and how it affects them in their daily lives and the world around them, which would further conservation for Soboba as a whole. In terms of education and conservation, preschool through 4th grade children are in their most formative years and this is the time to help them become ecologically aware. This age group is most open to suggestion and most likely to accept new ideas. If conservation is taught to the very young, they are more likely to carry the habits through a lifetime and pass them on to the next generation. Although the older children may not be as malleable as the younger group, this is the age group closest to making independent decisions about energy consumption and conservation. 
If interest and concern for energy conservation and ecological balance can be instilled in these youths, they will be the next group to assist the Tribe in moving forward with energy conservation goals. Examples of projects for the K-12 grade levels provided by DOE as well as a preschool project from the California Preschool Energy Efficiency Program are outlined below.

- Preschool - The project "Bright Ideas for Children" is used to introduce the idea of energy conservation to young children. There is an art project, a song and a counting project in this activity guide. A parental flyer with coordinating information is also included.

- Grades K-4 -Although there is not a school venue on the Reservation for this grade level, the project can be pursued by the Environmental Department in partnership with Soboba Tribal Temporary Assistance for Needy Families (TANF). A fun and useful project for this grade level is called "Draft-O-Meter." This project encourages both the creative and investigative areas of scientific discovery. The objectives are to learn to plan and conduct a simple investigation, employ simple tools, gather data, extend the senses and see how tools help scientists make better observations.

○ Grades 4-8 - The project "Waste Watchers" has the main objectives of having the students learn to identify ways to save energy in their daily lives and how saving energy can reduce air pollution.

- Grades 9-12 - After completing the project "Energy Efficiency Ambassadors," the students should be able to understand and discuss how using less energy helps our environment, the primary difference between compact fluorescent and incandescent light bulbs and other examples of energy-efficient technologies and/or energy-saving practices.

- Continue adult community outreach efforts that have been initiated. Community outreach efforts will not produce the largest savings in energy usage in the Tribe's business buildings. However, as awareness of energy conservation spreads to the Reservation residences through community outreach efforts; the overall reduction of energy consumption on the Reservation at large will increase exponentially. 
Additionally, outreach and awareness bring support for all manner of conservation/efficiency projects.

- Institute the Energy Fair as a yearly event to encourage more Tribal Member and employee community participation in energy awareness and conservation.

- Continue an annual Energy Awareness Month to keep the employees engaged and informed.

- Evaluate and replace/upgrade pump motors that are less than optimally efficient. There are a total of three pumps which supply the water for the Reservation buildings, homes and landscaping. Based on consultations with SCE, approximately 97,552 kWh per year would be conserved (this would result in over $2000 \mathrm{kWh}$ over the energy reduction goal for that year) by upgrading the pump motor for Well \#3 alone. A $\$ 14,000$ incentive is available from SCE towards the cost of the project. The cost of the project is estimated to be about $\$ 75,000.00$. An approximate savings of $\$ 13,000$ annually from the upgraded motor would result in a return on investment (ROI) of approximately five and a half years. Other pump motors on the Reservation should be evaluated to determine if this significant energy use reduction and savings could be extended beyond Well \#3.

- Encourage a program of water conservation for the sports fields, Tribal landscaping and the business buildings as well as Tribal residences. It is uncommon for people to realize the energy implications related to water usage. People rarely consider how much energy the Tribe is using to pump the water. As shown earlier in the chart on Tribal energy use, the pump houses are the greatest consumers of energy, accounting for more than one third of the annual kWh consumption. A program of water conservation for both business and residential use will show a decrease in energy consumption in this area and help the Tribe move towards their energy use reduction goal.

- The swimming pool pump motors have been evaluated by Hemet Pools and upgrading the pumps is recommended. The current energy use for one pump at the Sports Complex pool (there are four) is $13,392 \mathrm{kWh}$ annually. With a new variable speed pump the usage would fall to $5,232 \mathrm{kWh}$ annually for an annual savings of $8160 \mathrm{kWh}$ on one pump and 32,640 if all four were replaced. This would result in approximately one third of a single year's energy reduction goal and in the current market, this amounts to a 
savings of $\$ 2,369$ per pump annually. At an installed cost of approximately $\$ 1,700$, the ROI would be less than one year.

\section{Years Four and Five: Implement advanced projects}

- Lighting retro-fits should be conducted on both inside and outside fixtures. Inside lighting is recommended to be upgraded to LED. T-8 lighting (the type of fluorescent lighting used in the Administration building) will begin to phase out between 2014 and 2016, according to SCE and the Department of Energy. There will still be T-8 products available for several years after that, but this upgrade should occur as a year four or five project shortly after the phase out occurs. Energy Star indicates lighting usually provides the best ROI of major upgrades performed in commercial buildings. In 2010, the NESCO report noted that the Reservation could conserve $333 \mathrm{kWh}$ per year per large $175 \mathrm{~W}$ stadium light bulb replaced with a 40W LED light (if the practice of leaving the lights on 8-10 hours per night 8 months out of the year continued). At over 100 lights, that would conserve about 33,300 kWh of power annually. If the lights were both upgraded to LED and timers installed so the lights do not run after the sporting event is over, more kilowatts of energy might be conserved The figure of 33,300 $\mathrm{kWh}$ saved is nearly one third of the savings we would like to see annually.

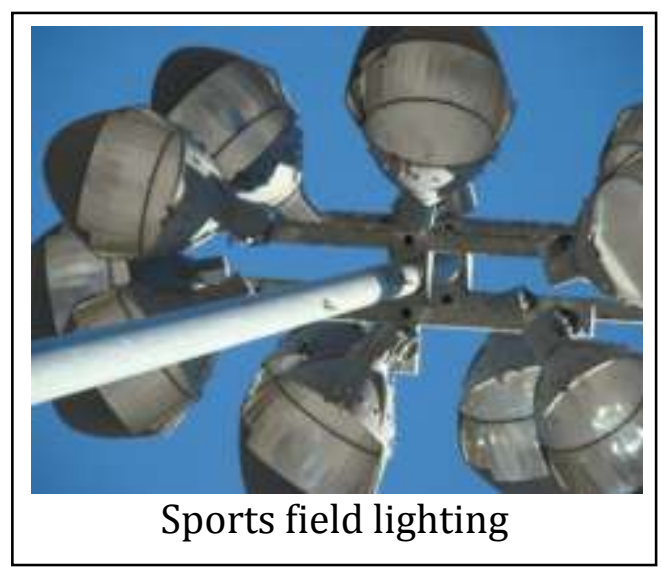

- Utilize solar energy through implementation of small scale projects. The use of renewable energy does not reduce the kilowatt hours of electricity used, but it would reduce dependence on fossil fuels and decrease greenhouse gas emissions. In the 2010 NESCO study, it was determined the Reservation's benefit from wind energy would be marginal and the utilization of solar energy is the most likely renewable energy to be used on the Reservation.

- SunPro Solar visited the Reservation and created a Solar Power Plan so that the approximate costs of a project, the return on investment time and the amount of energy which would be produced could be demonstrated. Both the location and the 
roofs on the Public Works buildings were optimal for this study. Public Works has a mostly flat, unshaded roof and solar panels are proposed for the western half. With the available roof space, SunPro Solar can construct a solar installation that will cover $75 \%$ of the energy consumption for the Public Works buildings. After state and local incentives, the final system cost was estimated at $\$ 292,000$. Based upon the current utility bill for Public Works and the cost of the solar installation, the return on investment would be approximately seven years. The current electricity usage for this facility is $47,329 \mathrm{kWh}$ annually and the installation of the proposed solar system would save $35,497 \mathrm{kWh}$ of electricity from being produced by SCE. Emission reductions would be realized right away. In the United States an average of approximately 1.3 pounds of $\mathrm{CO}_{2}$ (carbon dioxide) are released into the atmosphere per kWh of power generated from coal, petroleum, gas and other fuels emitting anthropogenic carbon dioxide according to a 2000 study conducted by the DOE and EPA. Therefore, this one modest solar installation for the Public Works building would benefit the atmosphere and decrease the carbon footprint of the Reservation by not releasing 23 tons of $\mathrm{CO}_{2}$ into the atmosphere annually.

- Investigate feasibility of installing green roofs. A green roof is covered with a layer of vegetation, growth medium and appropriate protection for the roof itself (see diagram). A green roof can serve several purposes. It can provide insulation, absorb rainwater, create a habitat for wildlife and help lower urban air temperatures to combat the heat island effect. The EPA gives approximate figures of $\$ 10$ per square foot to $\$ 25$ per square foot depending upon the type of plantings and planting materials used. The roof outside of the Administration building break room may be a suitable area to try this idea. Using the higher value from the EPA figures this would cost approximately $\$ 8,750$ to install on the roof outside the lunchroom window. 


\section{Basic Components of Green Roof}

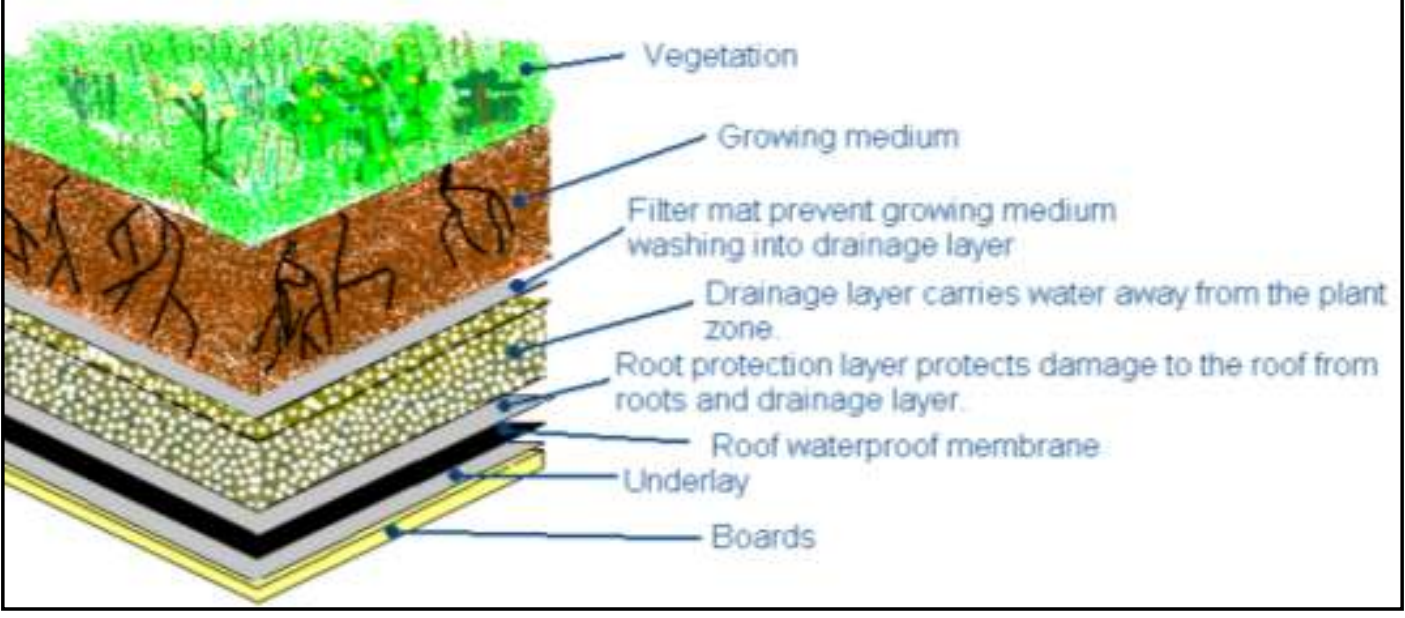

Potential benefits include:

- Waste diversion with the use of recycled materials for growth medium. The growth medium is about $80 \%$ inorganic materials to make sure it is very lightweight for use on the roof. The inorganic materials can include shredded tires and polypropylene.

- Increased insulation from both heat and cold to reduce demand on the HVAC system.

- Increased roofing membrane durability from decreased light and weather exposure. Although creating a green roof on an approximately 200 square foot roof section might not contribute to huge savings in kilowatt hours or money, it will create visible signs of appropriate stewardship of resources and may inspire further implementation that would result in significant energy savings.

- Use an alternative cooling system such as Coolerado from Energe Corp/Inland Strategies Group. Both Public Works and the Environmental Department have attended demonstrations of the Coolerado cooling unit and the unit was on display at the Energy Fair held in 2012. This unit is a new type of evaporative cooler using ground-breaking technology which uses the outside air, filters, cools, dehumidifies this air and then pushes the cooled air into the area to be air conditioned. The Federal Energy Management Program Report, Technology Installation Review states "This technology has the potential to have significant impact on an agency's energy bills in terms of 
reducing both energy and demand costs." According to this same report, performance tests have shown that the efficiency of the Coolerado Cooler is one and a half to four times higher than that of conventional vapor compression cooling systems, while it provides the same amount of cooling. Assuming the Coolerado system is one and a half times more efficient than the current system, 149,680 kWh of electricity could be saved each year by using it in the schools, Administration building, Public Works, Public Safety, TANF and the Tribal Hall.

\section{New Construction}

\section{New construction projects should implement green building practices}

Reducing emissions and increasing the efficiency of buildings are easiest to do when incorporated from the beginning of construction. Using green building practices in new construction will lower greenhouse gasses from the use of the building and automatically incorporate energy conservation/efficiency measures. According to the EPA, "Green building is the practice of creating structures and using processes that are environmentally responsible and resource-efficient throughout a building's life-cycle from siting to design, construction, operation, maintenance, renovation and deconstruction. Green buildings are designed to reduce the overall impact of the built environment on human health and the natural environment by:

- Efficiently using energy, water, and other resources

- Protecting occupant health and improving employee productivity

- Reducing waste, pollution and environmental degradation."

Some examples of green building practices pertaining to energy conservation include:

- Installation of sensors that detect when a room is empty or if there is enough sunlight to sufficiently light the room and automatically turn off the lights.

- Strategically placing energy efficient window throughout the building to utilize natural light.

- Implementing a plan to recycle all eligible wastes from the construction site.

- The use of high-grade insulation to lessen the heating and cooling needs of the building. 
- The use of Energy Star rated HVAC equipment to lessen the electrical usage load.

- The use of building materials from manufacturers and suppliers that are made from and transported by energy efficient methods.

The Tribe has asked that all new construction be Leadership in Energy and Environmental Design (LEED) certified. LEED is defined as by the Green Building Council as "An internationally recognized green building certification system that provides third-party verification that a building or community was designed and built using strategies aimed at improving performance across all the metrics that matter most: energy savings, water efficiency, CO2 emissions reduction, improved indoor environmental quality, and stewardship of resources and sensitivity to their impacts. Developed by the U.S. Green Building Council, LEED provides a concise framework for identifying and implementing practical and measurable green building design, construction, operations and maintenance solutions."

Credits can be earned from re-use of materials such as salvaged or refurbished materials, using materials with recycled content, using materials that are defined as rapidly renewable (planting and harvesting within a 10 year cycle or less), using wood products that are certified as being harvested in a sustainable manner and using low-emission products indoors such as paints, sealants and carpets. Points can also be earned from the use of energy efficient materials such as different types of insulation, led lighting, dual pane or tri-pane windows and from landscaping utilizing water conservation methods.

LEED certification and green building practices in general lower the consumption of resources compared to standard practices. These practices are cost effective for the Tribe as well as helpful in reducing the increase in energy consumption that regularly occurs with new construction.

\section{Upcoming projects}

At the current time, the Reservation is planning on constructing new buildings for the preschool, TANF and a multi-purpose room. The plan is for development on these projects to commence in the next year or two. The preschool is currently housed in the buildings that used to be the Soboba Health Clinic. These buildings were originally constructed more 
than 30 years ago, in the mid-to-late 1970's. Due to older construction methods, insulation and windows, they are not very energy efficient. TANF is currently housed in portables, which are not energy efficient. Public Works is planning for this new construction to be LEED certified and all new appliances will be Energy Star rated. The possibilities of alternative cooling technology and/or solar energy installation are also being addressed. All of these alternatives add up to projects that are cost effective, ecologically friendly, and conserve energy.

\section{Transportation}

Transportation is addressed because fuel savings are energy savings. For every gallon of gasoline not burned, approximately 20 pounds of carbon is not released into our atmosphere. Therefore any decrease in fuel use is not only cost effective for the Tribe, it is also conservation of energy (in the production and transportation of the fuel), which is in line with the Tribe's goals of energy consumption reduction. If each of the 19 regularly used vehicles for these departments used just one gallon of gas less per week that would translate to a savings of just over 980 gallons of gas annually. As each gallon of gas conserved keeps 20 pounds of carbon dioxide from being released into the atmosphere, emissions would be lowered by nearly 10 tons of carbon dioxide for that year. Summary of current vehicles, current fuel usage, and suggestions for improvement

The current fuel usage for the vehicles below totals approximately 6,000 gallons of gas annually. A survey of the tribally owned vehicles was conducted by the Soboba Tribal Energy Specialist. The Tribe operates several vehicles with lower mileage per gallon than other currently available, comparable models. As these vehicles need to be replaced, attention should be paid to the estimated gas mileage of each vehicle chosen and higher miles per gallon vehicles chosen where appropriate. The current vehicles are discussed below with their approximate gas mileage and possible better choices of similar size and engine performance. All the comparisons and better choices offered are based on city mileage estimates and on similar vehicles by body type and engine capability. 
- Public Works - The trucks for this department include the Ford F-250 and the Chevy Silverado. Their current mpg ratings range from an estimated 9-15 miles per gallon. There are hybrid models of similar vehicle types already available such as the GMC Sierra and Chevy Silverado with estimated EPA ratings of up to $23 \mathrm{mpg}$. If the Tribe preferred not to go with hybrid models, the Toyota Tacoma, Tundra and Highlander have models with EPA ratings of 16-28 mpg depending on model and engine size. Any of these options provides a decrease in fuel usage, which translates to a decrease in energy consumption, financial savings in the long run and the immediate benefit of the decrease in greenhouse gasses released into the atmosphere.

- Soboba Environmental Department and Cultural Department - Each department has a Jeep Wrangler which gets approximately 16-17 mpg. Environmental also has a Ford F150 which has an EPA mileage estimation of 14-18 mpg. In lieu of the jeeps, the Ford Escape hybrid might be a good replacement choice at 32 miles per gallon or the Toyota Highlander at $28 \mathrm{mpg}$. When the F-150 is ready to retire, both the Tundra and Tacoma have better gas mileage at 16-25 estimated mpg.

- Tribal Administration- The Tribe has a GMC Yukon, GMC Denali, a 25 passenger small bus and the "Krystal Party Van". Neither the bus nor the Party Van are used regularly, therefore they do not contribute much to fuel expenditure. The Denali $(13 \mathrm{mpg}$ ) from and the Yukon (15 mpg) are used on a regular basis (several times per week). The Toyota Highlander is similar in size and has better gas mileage at $20 \mathrm{mpg}$ and would be a suitable replacement when the Tribe is ready.

- TANF - TANF has a 2008 Ford E150 passenger van (9-13 mpg) and a 2006 Freestar mini-van (about 15mpg). The Freestar gets rather heavy usage going to and from Riverside about twice a day. The Ford E150 only sees about 30-50 miles per week of local driving. The Toyota Sienna would be the perfect replacement for the Freestar, seating the same amount of passengers and at $19 \mathrm{mpg}$ would conserve quite a lot of fuel. The E150 is a larger vehicle, seating 11 passengers with standard fuel usage for this size vehicle. The best solution for fuel use reduction on this vehicle is to combine trips and make sure the tires are inflated properly along with other efficiency measures to increase fuel economy 


\section{Future Organizational Resources}

SCE is a valuable resource for energy related projects as all of the Reservation's electricity is purchased from them at this time. Future partnership arrangements with SCE can include their input and technical assistance in matters such as evaluating the rest of the Reservation well pumps. Their expertise and information can be used to increase benefit cost ratio which will lead to more efficiency in projects completed. SCE can also assist in making sure the Tribe receives any rebates due for each project. They can double-check design and appliance/equipment purchases for any new constructions and re-models to make sure the Reservation's projects are as energy efficient as possible from inception to completion.

Contact has been made with several alternative energy companies including Horizon Solar, Trinity Energy Solutions, SolarPro and the Inland Strategies Group (Coolerado). The Tribe currently has introductory level relationships with all of these companies through events like the Energy Fair and Earth Day. SolarPro and Inland Strategies have had initial meetings to see what they might be able to do to further the Tribe's goal of lessening energy consumption and becoming involved in solar energy. Each of these companies has something to offer in the way of experience, products and expertise in regards to energy conservation or the introduction of renewable energy use.

\section{Conclusion}

There are several relatively simple projects that are outlined to begin reducing energy usage by $94,968 \mathrm{kWh}$ each year for the next five years. The following table summarizes the energy reduction methods mentioned in this plan that already have a quantifiable measure of $\mathrm{kWh}$ reduced. Over three years worth of energy reductions are put forth with estimates.

\begin{tabular}{|c|c|c|}
\hline Method & $\begin{array}{l}\mathrm{kWh} \text { reduced } \\
\text { (annually) }\end{array}$ & \% yearly goal \\
\hline $\begin{array}{l}\text { Adjust the thermostats in Public Works, Noli, Public Safety, } \\
\text { Administration, Tribal Hall, and Preschool }\end{array}$ & 8,980 & $9.5 \%$ \\
\hline Upgrade pump motor for Well \#3 & 97,552 & $102.7 \%$ \\
\hline $\begin{array}{l}\text { Upgrade pump motors for the Sports Complex Pool: } \\
\text { - One } \\
\text { - Four }\end{array}$ & $\begin{array}{l}\text { - } 8,160 \\
\text { - } 32,640\end{array}$ & $\begin{array}{ll}\text { - } & 8.6 \% \\
\text { - } & 34.4 \%\end{array}$ \\
\hline
\end{tabular}




\begin{tabular}{|l|l|l|}
\hline Method & $\begin{array}{l}\text { kWh reduced } \\
\text { (annually) }\end{array}$ & \% yearly goal \\
\hline $\begin{array}{l}\text { Replace stadium/parking lights (175W) with 40W bulbs } \\
\text { - One }\end{array}$ & $\begin{array}{l}\bullet 333 \\
\bullet \quad \text { All (approximately 100) }\end{array}$ & $\begin{array}{l}\bullet \\
\bullet\end{array}$ \\
\hline Solar panels placed on Public Works building & 35,4907 \\
\hline $\begin{array}{l}\text { Use of Coolerado system in schools, Administration, Public } \\
\text { Works, Public Safety, TANF and Tribal Hall }\end{array}$ & 149,680 & $37.4 \%$ \\
\hline Total of all methods & 357,649 & $157.6 \%$ \\
\hline
\end{tabular}

Soboba and the Tribal Environmental Department strive to lead by example in the field of conservation. In keeping with the skills and traditions that the ancestors passed down to the people of this land, the Tribe strives to be a ray of hope for the future of the natural resources on this Reservation. The Soboba Tribal Environmental Department has been active for over a decade and has utilized funding from the EPA to support such projects as water monitoring, solid waste clean-up, emissions inventories and the development of environmental codes and ordinances. Using the experience gathered through these previous projects, the department will champion the energy conservation strategies outlined in this plan. The Soboba Strategic Tribal Energy Plan has been formulated as a guide for the Tribe to achieve their goal of a $25 \%$ reduction in energy consumption over the next five years. Implementing and building upon the steps within this document will lead to significant gains in efficiency and energy use reduction, making the SSTEP goal a reality. 


\section{References}

California Preschool Energy Efficiency Program. Bright Ideas for Children. Retrieved March 13, 2013 from http://www.liifund.org/wpcontent/uploads/2011/03/English_CPEEPEdMaterials_LIIF.pdf.

Garland, Jay L. An Introduction to Green Roof Technology. Dynamic Corporation. Retrieved March 13, 2013 from http://Nasarecycles.nasa.gov/workshop_mar07/ JayGarlandAnIntroductiontoGreenRoofTechnology.pdf.

National Energy Services Company (NESCO). Energy Efficiency and Conservation Strategy Report for the Soboba Band of Luiseño Indians. December 30, 2010. Unpublished Work.

Southern California Edison. Power Content Label 2011. Retrieved May 15, 2013 from http://www.energy.ca.gov/sb1305/labels/2011_labels/SCE_PCL.pdf.

SunPro Solar. Solar Power Plan. Prepared for Dianna Greetan and the Soboba Band of Luiseño Indians. April 14, 2013. Unpublished Work.

US Department of Energy. Fuel Economy. Retrieved March 13, 2013 from www.fueleconomy.gov.

U.S. Department of Energy, Buildings Technologies Program. 2011 Buildings Energy Data Book. March 2012. Retrieved June 13, 2013 from http://buildingsdatabook.eren.doe.gov/docs\%5CDataBooks\%5C2011_BEDB.pdf.

US Department of Energy, Energy Education and Workforce Development. K-12 Lesson Plans \& Activities. Retrieved March 13, 2013 from http://www1.eere.energy.gov/education/lessonplans/default.aspx.

US Department of Energy, Federal Energy Management Program. Coolerado Cooler Helps to Save Cooling Energy and Dollars. March 2007. DOE/GO-102007-2325. Retrieved March 13, 2013 from http://www1.eere.energy.gov/femp/pdfs/tir_coolerado.pdf.

US Department of Energy, US Environmental Protection Agency. Carbon Dioxide Emissions from the Generation of Electric Power in the United States. July 2000. Retrieved March 13, 2013 from ftp://ftp.eia.doe.gov/environment/co2emiss00.pdf.

US Environmental Protection Agency. Energy Star. Retrieved June 18, 2013 from www.energystar.gov/index.cfm?c=sb_guidebook.sb_guidebook_lighting.

US Environmental Protection Agency. Green Building: Basic Information. Retrieved March 13, 2013 from http://www.epa.gov/greenbuilding/pubs/about.htm.

US Environmental Protection Agency. Green Roofs. Retrieved March 13, 2013 from www.epa.gov/heatisland/mitigation/greenroofs.htm. 
US Green Building Council. LEED. Retrieved June 18, 2013 from www.usgbc.org/leed 